\title{
BMJ Open Did the accuracy of oral amoxicillin dosing of children improve after British National Formulary dose revisions in 2014? National cross-sectional survey in England
}

Olivia Rann, ${ }^{1}$ Mike Sharland, ${ }^{2}$ Paul Long, ${ }^{3}$ Ian C K Wong, ${ }^{4}$ Anthony A Laverty, ${ }^{1}$ Alex Bottle, ${ }^{1}$ Charlotte I Barker, ${ }^{2}$ Julia Bielicki, $^{2}$ Sonia Saxena ${ }^{1}$

To cite: Rann 0 , Sharland M, Long $\mathrm{P}$, et al. Did the accuracy of oral amoxicillin dosing of children improve after British National Formulary dose revisions in 2014? National cross-sectional survey in England. BMJ Open 2017;7:e016363. doi:10.1136/ bmjopen-2017-016363

- Prepublication history for this paper is available online. To view these files, please visit the journal online (http://dx.doi. org/10.1136/bmjopen-2017016363).

Received 12 February 2017 Revised 12 July 2017

Accepted 27 July 2017

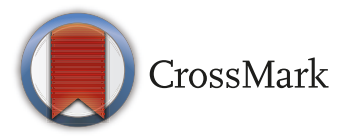

${ }^{1}$ Department of Primary Care and Public Health, Imperial College London, London, UK ${ }^{2}$ Paediatric Infectious Diseases Research Group, St George's University of London, London, UK

${ }^{3}$ Department of Pharmaceutical Science, King's College London, London, UK

${ }^{4}$ Department of Practice and Policy, University College London, London, UK

Correspondence to Prof Sonia Saxena; s.saxena@imperial.ac.uk

\section{ABSTRACT}

Objectives Inaccurate antibiotic dosing can lead to treatment failure, fuel antimicrobial resistance and increase side effects. The British National Formulary for Children (BNFC) guidance recommends oral antibiotic dosing according to age bands as a proxy for weight. Recommended doses of amoxicillin for children were increased in 2014 'after widespread concerns of under dosing'. However, the impact of dose changes on British children of different weights is unknown, particularly given the rising prevalence of childhood obesity in the UK. We aimed to estimate the accuracy of oral amoxicillin dosing in British children before and after the revised BNFC guidance in 2014.

Setting and participants We used data on age and weights for 1556 British children (aged 2-18 years) from a nationally representative cross-sectional survey, the Health Survey for England 2013.

Interventions We calculated the doses each child would receive using the BNFC age band guidance, before and after the 2014 changes, against the 'gold standard' weight-based dose of amoxicillin, as per its summary of product characteristics.

Primary outcome measure Assuming children of different weights were equally likely to receive antibiotics, we calculated the percentage of the children who would be at risk of misdosing by the BNFC age bands.

Results Before $2014,54.6 \%$ of children receiving oral amoxicillin would have been underdosed and no child would have received more than the recommended dose. After the BNFC guidance changed in 2014, the number of children estimated as underdosed dropped to $5.8 \%$, but $0.5 \%$ of the children would have received too high a dose. Conclusions Changes to the BNFC age-banded amoxicillin doses in 2014 have significantly reduced the proportion of children who are likely to be underdosed, with only a minimal rise in the number of those above the recommended range.

\section{BACKGROUND}

Over a third of British children receive an antibiotic each year, and more than half of
Strengths and limitaions of this study

- Strengths of this study are that this is the first study to evaluate this major change in children's antibiotic dosing guidance in Britain.

- Use of a large nationally representative sample of the UK child population.

- Limitations of this study are that there was no data for children under 2 years of age.

- Assumption that all children are equally likely to be prescribed antibiotics.

- Assumption that clinicians are adhering to the guidelines.

these are oral penicillins, most frequently for otitis media, symptoms of sore throat and cough. ${ }^{1-3}$ The majority of antibiotic prescriptions are unnecessary given that most infectious illnesses are viral or have a low riskto-benefit ratio, ${ }^{45}$ but when they are required it is important they are dosed appropriately. Inaccurate dosing of antibiotics may expose children to iatrogenic harm. Subtherapeutic antibiotic dosing can lead to treatment failure and fuel antimicrobial resistance, while excessive doses could increase the incidence and severity of side effects and toxicity. ${ }^{67}$ Paediatric drug dosing is more complex than in adults and should ideally reflect the age and weight of the child. The age-banding system used for prescribing paediatric oral antibiotics in the UK has the benefits of not requiring an up-to-date weight on the child and streamlines prescriptions to avoid more error-prone drug measurements. ${ }^{8}$ However, given that the weights of children do not change in a linear fashion with age, the UK's age-banding system is more likely to result in suboptimal dosing than in continental Europe, where prescriptions are typically 
Table 1 British National Formulary for Children (BNFC) oral amoxicillin doses before and after 2014 guidance change

Paediatric oral amoxicillin dosing-standard dose

\begin{tabular}{llll}
\hline Pre-BNFC 2014 change: BNFC 2013-2014 & \multicolumn{2}{l}{ Post-BNFC 2014 change: BNFC 2014-2015 } \\
\hline Age & Three times daily dose & Age & Three times daily dose \\
$<1$ month & $30 \mathrm{mg} / \mathrm{kg}$ & $<1$ month & $30 \mathrm{mg} / \mathrm{kg}$ \\
1 month-1 year & $62.5 \mathrm{mg}$ & 1 month-1 year & $125 \mathrm{mg}$ \\
1 year-5years & $125 \mathrm{mg}$ & 1 year-5years & $250 \mathrm{mg}$ \\
5 years-18years & $250 \mathrm{mg}$ & 5 years-12 years & $500 \mathrm{mg}$ \\
& & 12 years-18years & $500 \mathrm{mg}$ \\
\hline
\end{tabular}

calculated according to weight (ie, milligrams per kilogram per dose). ${ }^{8}$ This is further complicated because the few original pharmacokinetic and pharmacodynamics studies predate rising trends for obesity in children. ${ }^{8-10}$

A relatively arbitrary principle of halving adult oral penicillin doses for older children and again for younger children to infants was initially applied in the $1960 \mathrm{~s}^{11}$ Amoxicillin bands, which were originally published in the 1976-1978 British National Formulary, the main reference source for drug prescribing in the UK, remained in place for many years and were generally not questioned until 2011. ${ }^{10}$ In 2014, the British National Formulary for Children (BNFC) changed its amoxicillin age-banded doses for children to 'come in line with European recommendations after widespread concerns of under dosing' were reported in children receiving amoxicillin in primary care. ${ }^{6}$ Current guidelines still recommend age bands, with dosing increased if necessary up to $30 \mathrm{mg} / \mathrm{kg}$ three times a day. Three times daily dosing is favoured due to the short half-life of amoxicillin. The dose for each age band has been doubled, when compared with the former standard dose for all age groups (table 1).

Despite the changes, previous simulations have shown up to $18 \%$ of British children admitted to hospital would receive amoxicillin doses outside the recommended guidance when age bands are used. ${ }^{8}$ However, children admitted to hospital may have a different distribution of weight compared with those in the community, one in three of whom is overweight by the age of 11 years. In this study, we aimed to evaluate the impact of this guidance change by estimating the percentage of British children receiving too high or too low a dose of oral amoxicillin according to their weights before and after changes to the BNFC in 2014.

\section{METHODS}

Although electronic records are available in primary care detailing drug doses, there is no systematic weight monitoring at or near the time of drug prescribing for children. Therefore we estimated the dose of amoxicillin a child would have received both before and after the BNFC 2014 guidance change using a nationally representative cross-sectional survey of British children's weights. We used data on age and weights for 1556 British children (aged 2-18 years) from the most recent Health Survey for England 2013 (HSE 2013). ${ }^{12}$ We assumed that the BNFC guidance is followed and that children of different weights and ages were equally likely to receive antibiotics, and then estimated the doses each child would receive using the BNFC age band guidance, before and after the 2014 changes (see table 1). We compared these against an assumed 'gold standard' of weight-based dosing for amoxicillin $^{13}$ (see table 2). Our main outcome was the risk of underdose or overdose, defined as the percentage of children who would theoretically receive a dose outside the suggested summary of product characteristics' (SPC) limits. ${ }^{13}$

To allow comparisons across age categories that slightly differed between 2013/2014 and 2014/2015 BNFC guidance, we included children up to their fifth birthday in the category of children aged 1-5 years old (table 1 ). We were unable to examine impact of dosing changes in infants using these data because the HSE includes only children aged 2 years and above. We analysed the statistical significance of the change in risk of underdosing or overdosing using $\mathrm{X}^{2}$ tests. We performed these analyses among the population overall, as well as individually for children above and below the $40 \mathrm{~kg}$ cut-off.

\section{RESULTS}

The HSE 2013 had data on age and weights for 1556 children aged 2-18 years old. Of these $881(56 \%)$ weighed less than $40 \mathrm{~kg}$ and 675 (43\%) were over $40 \mathrm{~kg}$. We estimated that before the BNFC guidance change, 850

Table 2 Dosing limits of amoxicillin defined by the summary of product characteristics ${ }^{13}$

\begin{tabular}{lll} 
& \multicolumn{2}{c}{ Amoxicillin paediatric dosing range } \\
\cline { 2 - 3 } & Lower limit & Upper limit \\
\hline Children $<40 \mathrm{~kg}$ & $40 \mathrm{mg} / \mathrm{kg} /$ day & $\begin{array}{l}90 \mathrm{mg} / \mathrm{kg} / \text { day } \\
\text { (not exceeding } 3 \mathrm{~g} / \\
\text { day) }\end{array}$ \\
Children $>40 \mathrm{~kg}$ & 'As per Adult & $\begin{array}{l}\text { 'As per Adult dosing': } \\
\text { dosing': } \\
\text { standard lower limit } \\
\text { stand maximum is } \\
\text { 750 } \mathrm{mg} / \text { day }\end{array}$ \\
\hline
\end{tabular}


$(54.6 \%)$ of children receiving oral amoxicillin would have been underdosed. After the guidance changed, this number fell to $91(5.8 \%) \quad(\mathrm{p}<0.001)$. Prior to 2014 , none of the children would have received more than the recommended dose, but after the guidance changed we estimated that eight $(0.5 \%)$ of the children would have received too high a dose $(\mathrm{p}<0.001)$ (table 3$)$. A sensitivity analysis showed that all these children were aged 5 years. Although the higher doses ranged from $2 \%$ to $14 \%$ above the recommended limit, only one of these children would have received an overdose of more than $10 \%$.

The improvements in underdosing mainly benefited older children, whereas around one in three children aged 4 years was still likely to receive less than the recommended dose (figure 1). Despite the change, 91 of 881 $(10.3 \%)$ children with a weight less than $40 \mathrm{~kg}$ were still underdosed after the guidance changed, but all 675 children weighing over $40 \mathrm{~kg}$ in our sample received the correct dose after the changes.

\section{DISCUSSION}

Changes to the BNFC age-banded oral amoxicillin doses in 2014 have significantly increased the chances that children will get the correct dose from $46 \%$ to $94 \%$, dramatically reducing the risk of underdosing in children. This is offset by only a very small rise in the number at risk of being dosed above the recommended range. Applying these percentages to current estimations on population size of the British birth cohort, ${ }^{14}$ approximately 7.5 million children and young people aged less than 18 years were at risk of being underdosed when prescribed oral amoxicillin prior to the guidance change, which is now reduced to approximately 790000 . Against this, the revised guidance puts approximately 68000 children at increased risk of receiving a slightly higher dose $(2 \%-14 \%)$ than the recommended limit for children, although there is little evidence to suggest this would be harmful.

\section{Strengths and weaknesses in relation to previous studies}

Ours is the first study to evaluate a major change in children's antibiotic dosing guidance in Britain.

In using the latest HSE, we were able to estimate the theoretical impact of the guidance change on the most recent large nationally representative sample of the UK child population. Although good quality data on prescribing are available from within routine electronic records, there are currently no systematically recorded data on the weights of children taken around the time of prescribing antibiotics in primary care available to model and examine dosing accuracy. However there are significant challenges to measuring the impact of changes in drug dosing guidance in a large population that may limit the validity and generalisability of our findings.

First, these data only include children who are aged 2 years or older. Children aged less than 2 years make up approximately $18.7 \%{ }^{14}$ of the paediatric population, receiving a significant proportion of paediatric antibiotic prescriptions, ${ }^{15}$ and fall into the under $40 \mathrm{~kg}$ category, so are more likely to have been affected by the guidance changes. Second, our estimations assumed that all children are equally likely to be prescribed antibiotics. However, incidence of acute bacterial infections is higher among preschool children, and there is some evidence that very underweight children $(<3$ rd centile) may be at higher risk of such infections. ${ }^{16}{ }^{17}$ Hence our estimation will overestimate 'correct' dosing for these groups.

A third source of error is using the SPC as a gold standard to provide the upper and lower boundaries of prescribing. Pharmacokinetic studies in children on which the 'gold standard' weight-based guidance is based are limited and may explain an internal inconsistency within the SPC. The minimum acceptable dose of oral amoxicillin for a child weighing between $18.75 \mathrm{~kg}$ and $40 \mathrm{~kg}$ is higher than that accepted for an adult (because $40 \mathrm{mg} / \mathrm{kg}$ /day is more than $750 \mathrm{mg}$ at weights greater than $18.75 \mathrm{~kg}$ ). There is evidence for aiming for higher doses within the $40-90 \mathrm{mg} / \mathrm{kg} /$ day range to treat acute otitis media in children, ${ }^{18} 19$ and this mismatch between acceptable levels in children and adult has previously been identified. ${ }^{20}$ Another example of this is that there appears to be a non-linear relationship of obesity and drug exposure ${ }^{21}$ that may be a source of bias in our estimations. Defining appropriate dosing is also condition-specific, something we have not accounted for, for example, with higher doses recommended in acute otitis media compared with pharyngitis.

Finally our estimations also assume that clinicians are following the guidelines. Previous research suggests this is not necessarily the case, ${ }^{6}$ but this has not been evaluated since the guidance change. Our pre-2014 guidance change findings are consistent with Ahmed $e t a l \mathrm{~s}^{10}$ calculations on average weights from HSE 2011, which suggested significant underdosing. Bielicki $e t a l^{8}$ recently looked at the post-2014 BNFC guidance change for children weighing less than $40 \mathrm{~kg}$ admitted to hospital. The rates for underdosing were similar ( $7 \%$ vs our $10.3 \%)$, but they found $11 \%$ of children to be receiving above recommended doses compared with our study $(0.9 \%)$. This may be explained by a sicker population of children seen in hospital compared with those treated in the community.

\section{Implications and future research}

Our findings suggest that the recent BNFC 2014 oral amoxicillin age band dosing changes will have resulted in more optimal prescribing. Although this is a significant improvement in favour of evidence-based prescribing, there may be a need to raise awareness among prescribers about these changes. Doing so may also provide a further opportunity for emphasising the need for judicious antibiotic use. What is not clear from this theoretical model is how these dosing variations impact on clinical outcomes. Answering this question poses significant methodological challenges for research because many children are prescribed antibiotics who may not need them. Despite a substantial evidence base suggesting that penicillin has 


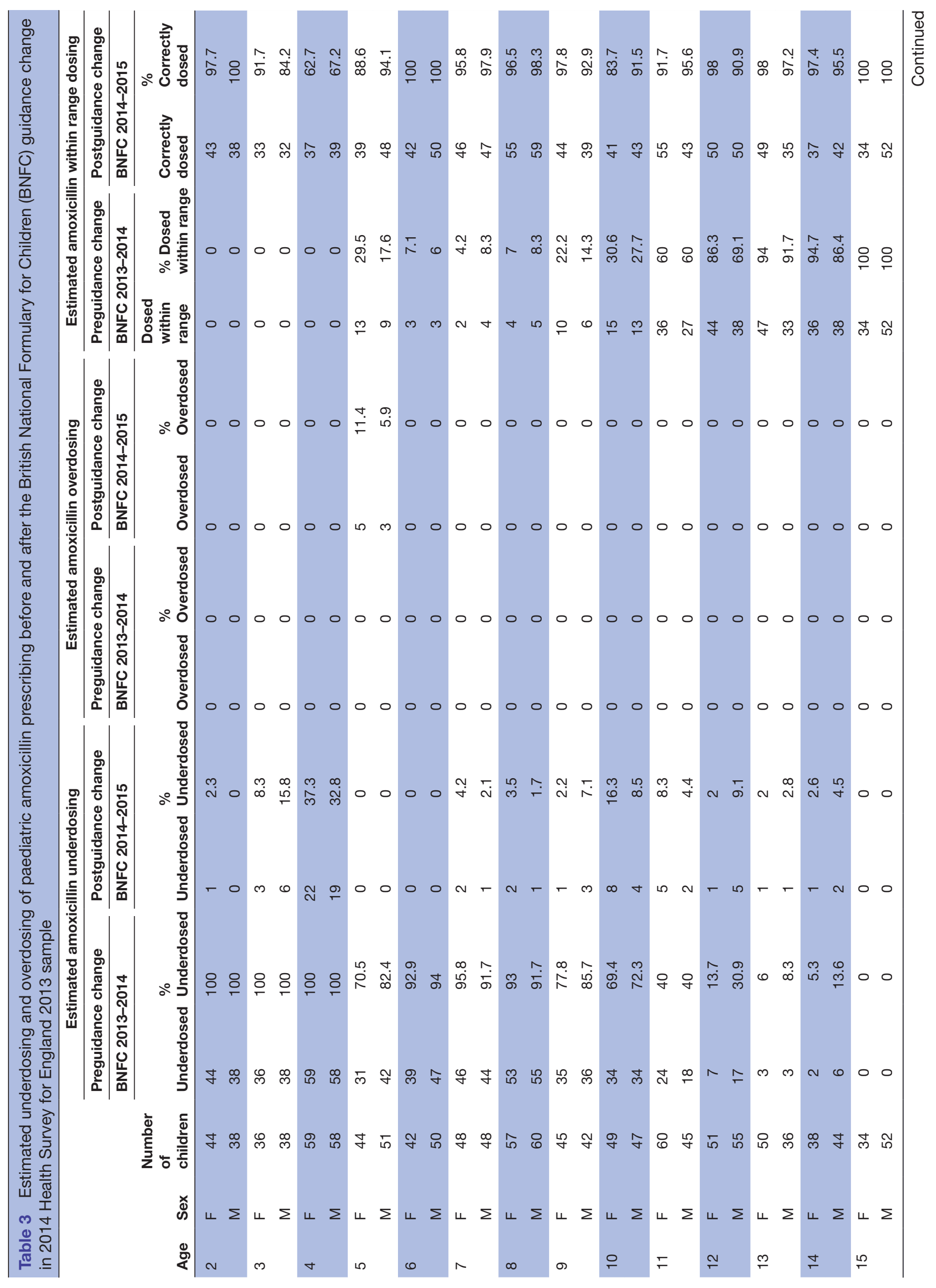




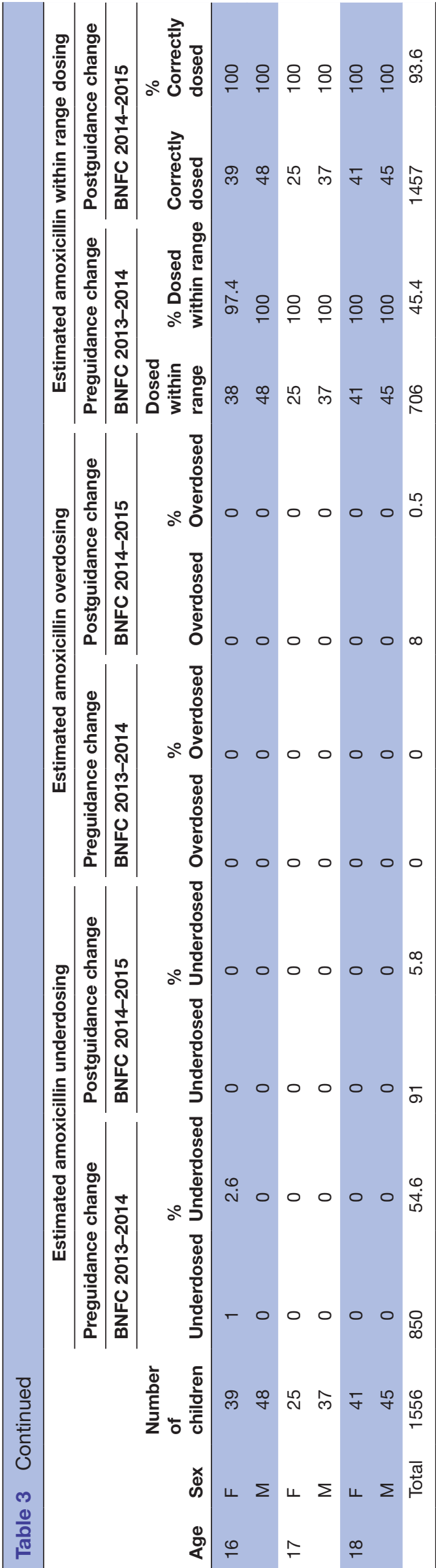

Before BNFC 2014 Guidance Change

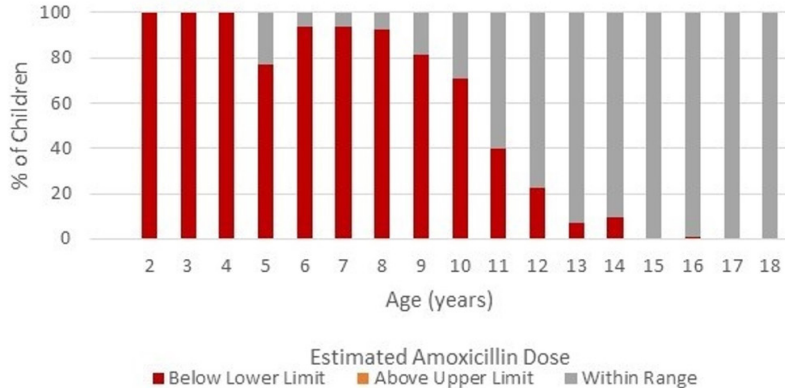

After BNFC 2014 Guidance Change

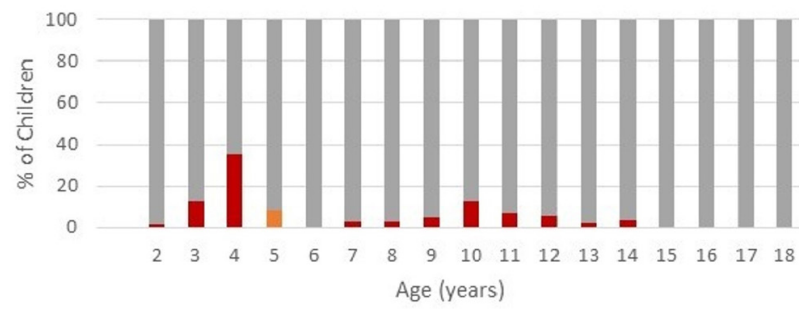

Estimated Amoxicillin Dose

- Below Lower Limit above Upper Limit Within Range

Figure 1 Estimated proportion of inappropriate dosing of oral amoxicillin before and after the British National Formulary for Children (BNFC) guidance change in 2014, calculated using weights and ages of 1556 children from the Health Survey for England 2013.

limited benefits for acute sore throat, otitis media and other respiratory conditions in children, ${ }^{45}$ antibiotic prescribing in British primary care remains relatively high. ${ }^{22-24}$ Antibiotic prescribing in primary care also varies widely between physicians, who are not solely motivated by a belief in drug efficacy. Patients' expectations are sometimes cited as a reason for prescribing, underpinned by workload pressures, difficulties in doctorpatient communication and diagnostic uncertainty. ${ }^{25}$ More research may be useful to understand whether physicians prescribe differential doses according to their prescribing intention. Given the continued rise in childhood obesity, it may well be prudent to review other paediatric antibiotic guidelines accordingly. As well as the doses themselves, should we be questioning the dosing selection system: the appropriateness of the age-banding system versus a weight based system? The former enables simple prescribing with no need for an up-to-date weight but is risking increased dosing inaccuracy. ${ }^{8}$ We recommend more studies are undertaken to examine the pharmacokinetics of antibiotics in overweight and underweight children.

Contributors SS conceptualised and designed the study. OR carried out the initial analysis and drafted the initial manuscript. SS, AAL and AB coordinated data collection and supervised data analysis. All authors (SS, OR, MS, PL, ICKW, AAL, $A B, C I B, J B$ ) critically reviewed and revised the manuscript and approved the final manuscript as submitted. 
Funding SS was funded by National Institute for Health Research (Career Development Fellowship CDF-2011-04-048). This study presents independent research funded by the National Institute for Health Research (NIHR). The views expressed in this publication are those of the authors and not necessarily those of the NHS, the NIHR or the Department of Health. AB is part funded by Dr Foster, a Telstra Health company providing healthcare information. CIB was funded as a Clinical Research Fellow by the Global Research in Paediatrics Network of Excellence (GRiP), part of the European Union's Seventh Framework Programme for research, technological development and demonstration (FP7/2007-2013, Grant Agreement Number 261060). The sponsors of the study had no role in study design, data collection, data analysis, data interpretation or writing the report. The corresponding author had full access to all the data in the study and had final responsibility for the decision to submit for publication.

Competing interests None declared.

Provenance and peer review Not commissioned; externally peer reviewed.

Data sharing statement № additional data available.

Open Access This is an Open Access article distributed in accordance with the Creative Commons Attribution Non Commercial (CC BY-NC 4.0) license, which permits others to distribute, remix, adapt, build upon this work non-commercially, and license their derivative works on different terms, provided the original work is properly cited and the use is non-commercial. See: http://creativecommons.org/ licenses/by-nc/4.0/

(c) Article author(s) (or their employer(s) unless otherwise stated in the text of the article) 2017. All rights reserved. No commercial use is permitted unless otherwise expressly granted.

\section{REFERENCES}

1. Holstiege J, Schink T, Molokhia M, et al. Systemic antibiotic prescribing to paediatric outpatients in 5 European countries: a population-based cohort study. BMC Pediatr 2014;14:174.

2. Clavenna $A$, Bonati M. Differences in antibiotic prescribing in paediatric outpatients. Arch Dis Child 2011;96:590-5.

3. Sharland M. SACAR Paediatric Subgroup. The use of antibacterials in children: a report of the Specialist Advisory Committee on Antimicrobial Resistance (SACAR) Paediatric Subgroup. J Antimicrob Chemother 2007;60(Suppl 1):i15-i26.

4. Keith T, Saxena S, Murray J, et al. Risk-benefit analysis of restricting antimicrobial prescribing in children: what do we really know? Curr Opin Infect Dis 2010;23:242-8.

5. Thompson PL, Gilbert RE, Long PF, et al. Effect of antibiotics for otitis media on mastoiditis in children: a retrospective cohort study using the United kingdom general practice research database. Pediatrics 2009;123:424-30.

6. Saxena S, Ismael Z, Murray ML, et al. Oral penicillin prescribing for children in the UK: a comparison with BNF for Children age-band recommendations. Br J Gen Pract 2014;64:e217-e222.

7. Thompson PL, Spyridis N, Sharland M, et al. Changes in clinical indications for community antibiotic prescribing for children in the
UK from 1996 to 2006: will the new NICE prescribing guidance on upper respiratory tract infections just be ignored? Arch Dis Child 2009;94:337-40.

8. Bielicki JA, Barker Cl, Saxena S, et al. Not too little, not too much: problems of selecting oral antibiotic dose for children. BMJ 2015;351:h5447.

9. Schaad UB, Casey PA, Cooper DL. Single-dose pharmacokinetics of intravenous clavulanic acid with amoxicillin in pediatric patients. Antimicrob Agents Chemother 1983;23:252-5.

10. Ahmed U, Spyridis N, Wong IC, et al. Dosing of oral penicillins in children: is big child=half an adult, small child=half a big child, baby=half a small child still the best we can do? BMJ 2011;343:d7803.

11. Cole FM. Pediatric prescribing treatment of infections in childhood. Br Med J 1963;2:1577-8 CONTD.

12. Unit JHS. The health survey for England England. 2013.

13. MHRA. Medicines and Products Regulatory Agency PAR Amoxicillin Sugar Free Suspension BP $125 \mathrm{mg} / 5 \mathrm{ml}$ and $250 \mathrm{mg} / 5 \mathrm{ml}$ 2016. http:// www.mhra.gov.uk/home/groups/par/documents/websiteresources/ con140627.pdf.

14. Statistics OfN. 2016: http://ons.gov.uk/ons/taxonomy/index.html? nscl=Population.

15. Sturkenboom MC, Verhamme KM, Nicolosi A, et al. Drug use in children: cohort study in three European countries. BMJ 2008;337:a2245.

16. Black RE, Victora CG, Walker SP, et al. Maternal and child undernutrition and overweight in low-income and middle-income countries. Lancet 2013;382:427-51.

17. Caulfield LE, de Onis M, Blössner M, et al. Undernutrition as an underlying cause of child deaths associated with diarrhea, pneumonia, malaria, and measles. Am J Clin Nutr 2004;80:193-8.

18. Lieberthal AS, Carroll AE, Chonmaitree T, et al. The diagnosis and management of acute otitis media. Pediatrics 2013;131:e96 4-e999.

19. Canafax DM, Yuan Z, Chonmaitree T, et al. Amoxicillin middle ear fluid penetration and pharmacokinetics in children with acute otitis media. Pediatr Infect Dis J 1998;17:149-56.

20. Christian-Kopp S, Sinha M, Rosenberg DI, et al. Antibiotic dosing for acute otitis media in children: a weighty issue. Pediatr Emerg Care 2010;26:19-25.

21. Harskamp-van Ginkel MW, Hill KD, Becker KC, et al. Drug dosing and pharmacokinetics in children with obesity: a systematic review. JAMA Pediatr 2015;169:678-85.

22. Spinks A, Glasziou PP DMCB. Antibiotics for sore throat. Cochrane Database Syst Rev 2013;11:CD000023.

23. Venekamp RP, Sanders SL, Glasziou PP, et al. Antibiotics for acute otitis media in children. Cochrane Database Syst Rev 2015;6:CD000219.

24. Spurling GK, Del Mar CB, Dooley L, et al. Delayed antibiotics for respiratory infections. Cochrane Database Syst Rev 2013;4:CD004417.

25. Fletcher-Lartey S, Yee M, Gaarslev C, et al. Why do general practitioners prescribe antibiotics for upper respiratory tract infections to meet patient expectations: a mixed methods study. BMJ Open 2016;6:e012244. 